\title{
Inflação, Desemprego e Choques Cambiais: \\ Estimativas VAR para a Economia Brasileira
}

\section{Inflation, Unemployment and Exchange Rate Shocks: a VAR Estimation for the Brazilian Economy}

\author{
Adolfo Sachsida* \\ Bernardo Patta Schettini** \\ Raphael Rocha Gouvêa***
}

\begin{abstract}
Resumo: Este artigo estima um modelo de vetores autorregressivos (VAR) representando a curva de Phillips novo keynesiana com choques cambiais. A taxa de desemprego da Pesquisa Mensal de Emprego (PME) do IBGE é a proxy para o custo marginal, a inflação é medida pelo Índice Nacional de Preços ao Consumidor Amplo (IPCA) e as expectativas foram obtidas do boletim Focus do Banco Central do Brasil. Os resultados indicam que: a) o pass-through cambial é de cerca de 0,04 p.p. na inflação do mês seguinte ao choque de $\mathrm{R} \$ 0,01$ no preço do dólar (mais de 0,4 p.p. na inflação anualizada), mas esse efeito é insignificante; b) um choque médio na taxa de desemprego demora ao redor de 18 meses para desaparecer; c) uma inovação de 0,06 p.p. na expectativa de inflação é carregada para a inflação, que atinge um máximo de 0,05 p.p. no mês seguinte ao choque (0,6 p.p. na inflação anualizada); e d) choques na série de inflação não afetam a taxa de desemprego, isto é, mais inflação não reduz o desemprego.
\end{abstract}

Palavras-chave: Inflação. Desemprego. Choques cambiais. Curva de Phillips.

Abstract: This paper estimates a VAR model representing the new-Keynesian Phillips curve with exchange rate shocks for the Brazilian economy. The unemployment rate from the PME survey is our proxy for the marginal cost, inflation is measured by the CPI, and expectations were obtained from the Central Bank survey with the financial market. The empirical findings may be summed up in the following: a) the exchange rate pass-through is around 0.04 p.p. to the next month inflation (above 0.4 p.p. in the annualized rate) after an exogenous variation of $\mathrm{R} \$ 0,01$ in the dollar price, but this effect is insignificant; b) a shock on the unemployment rate lasts around 18 months; c) an innovation of 0,06 p.p. on expectations is carried to inflation which is increased by 0,05 p.p. in the month following the shock (0.6 p.p. over the annualized inflation); and d) a shock on the inflation rate has no effect over the unemployment rate, that is, more inflation does not reduce unemployment.

\footnotetext{
Doutor em Economia pela Universidade de Brasília (UNB). Pesquisador do Instituto de Pesquisa Econômica Aplicada (IPEA). E-mail: adolfo.sachsida@ipea.gov.br

** $\quad$ Mestre em Economia pela Universidade Federal de Minas Gerais (UFMG). Pesquisador do IPEA. E-mail: bernardo.schettini@ipea.gov.br

*** Mestre em Economia pela Universidade de São Paulo (USP). Pesquisador do IPEA. E-mail: raphael.gouvea@ipea.gov.br
} 
Keywords: Inflation. Unemployment. Exchange rate shocks. Phillips curve.

JEL Classification: E31; E24; C32.

\section{1 lntrodução}

A curva de Phillips descreve a relação entre inflação e desemprego. Tal relação foi proposta há mais de meio século, mas ainda permanece no centro do debate macroeconômico atual. A importância dessa relação pode ser comprovada pelo fato de estudos sobre a curva de Phillips serem comuns na maioria dos bancos centrais ao redor do mundo, principalmente naqueles que adotam o regime de metas de inflação (HARGREAVES; KITE; HODGETTS, 2006). Não é incomum que pesquisadores classifiquem a curva de Phillips como uma das mais importantes relações estudadas na macroeconomia (ANNABLE, 2007). Essa afirmação tem como base os avanços teóricos feitos por Clarida, Galí e Gertler (1999) e Svensson (2000), que mantêm a curva de Phillips no centro do debate macroeconômico moderno.

A curva de Phillips novo keynesiana - um modelo de fixação de preços com rigidez nominal que implica que a inflação pode ser explicada pela evolução esperada dos custos marginais reais (COGLEY; SBORDONE, 2006) - serve de base para uma extensa literatura referente à dinâmica inflacionária. Nos últimos anos, o debate empírico sobre a validade da curva de Phillips tem se acirrado. Se, por um lado, os estudos de Galí e Gertler (1999) e Galí, Gertler e López Salido (2001) apresentam resultados estatísticos favoráveis à curva de Phillips, há também os estudos de Rudd e Whelan (2005), Lindé (2005) e Bårdsen, Jansen e Nymoen (2004) sugerindo que a relevância empírica da curva de Phillips deve ser considerada fraca.

Para países desenvolvidos, a pesquisa recente sobre a curva de Phillips é extensa. Atualmente, pode-se dividir os estudos em dois tipos: aqueles que propõem inovações teóricas e os que elaboram estimativas econométricas mais sofisticadas. Do ponto de vista teórico, Annable (2007) deriva um modelo que inclui uma estratégia eficiente para ajustar salários à inflação. Essa inovação aumenta a importância das expectativas racionais sobre a inflação futura. A importância de se adotar uma taxa de desconto diferente de zero num modelo de equilíbrio geral é ressaltada por Karanassou e Snower (2006), que mostram que tal mudança pode gerar alto grau de persistência inflacionária e um trade-off de longo prazo entre inflação e desemprego. Nos últimos anos, uma das principais inovações teóricas foi sugerida por Mankiw e Reis (2002), que adotam o conceito de rigidez de informação, em vez da tradicional rigidez de preços, para derivar a curva de Phillips, mudança que é capaz de gerar um grau de inércia inflacionária mais similar aos observados nos dados. 
No campo econométrico, as principais inovações residem nas diferentes estimativas da expectativa de inflação, tal como sugerido por Henzel e Wollmershäuser (2008). A necessidade de restrições adicionais sobre os parâmetros também tem sido objeto de estudo, como, por exemplo, o de Blanchard e Galí (2007), que argumentam sobre a necessidade de restrições conjuntas sobre os parâmetros da variável inflação futura e inflação passada. Cogley e Sbordone (2006) sugerem que a inclusão de um salto (drift) na estimativa de tendência inflacionária melhora a estimativa da dinâmica inflacionária no curto prazo. Por fim, a questão de quais proxies deve-se adotar também ocupa lugar no debate (SBORDONE, 2002). Galí, Gertler e López Salido (2005) sugerem que a proxy para o custo marginal deve estar associada à massa salarial, e não ao hiato do produto. Mankiw (2001) também critica o uso do hiato do produto para a estimativa da curva de Phillips. No entanto, essa questão também não é clara, uma vez que vários estudos utilizam hiato do produto ou algo semelhante como variáveis de controle.

Em relação ao Brasil, a habilidade da curva de Phillips de descrever a dinâmica inflacionária nacional tem sido bastante estudada. Tal como acontece com a literatura internacional, os trabalhos brasileiros adotam geralmente técnicas estatísticas de séries temporais, diferindo apenas em dois quesitos: nas proxies adotadas para representar a inflação e o custo marginal das empresas; e no método econométrico específico empregado. Cabe destacar as contribuições importantes de Areosa, McAleer e Medeiros (2011), Arruda, Ferreira e Castelar (2011) e Correa e Minella (2010), que estimam modelos não lineares para a curva de Phillips brasileira. Sachsida, Ribeiro e Santos (2009) mostram evidências de que os resultados são extremamente sensíveis às proxies adotadas para representar o custo marginal. Quanto a esse aspecto, cumpre citar o esforço empreendido por Sachsida, Mendonça e Medrano (2011), que examinam um conjunto amplo e variado de dados, assim como diferentes especificações econométricas, incluindo modelos frequentistas e bayesianos. Além desses, há vários outros estudos que analisam a experiência brasileira (que serão descritos mais à frente), como, por exemplo, os de Portugal, Madalozzo e Hilllbrecht (1999), Lima (2003), Fasolo e Portugal (2004), Muinhos (2004), Araujo, Areosa e Guillén (2004), Alves e Areosa (2005), Schwartzman (2006) e Mazali e Divino (2010).

O objetivo deste estudo é encontrar uma representação de vetores autorregressivos (VAR) da curva de Phillips brasileira incluindo choques na taxa de câmbio. Os dados são mensais e cobrem o período de 2002 a 2011.

O método VAR apresenta algumas vantagens: a) leva em consideração toda a dinâmica existente nos dados; b) a estimação pode ser feita via mínimos quadrados (exceto as funções de impulso resposta); e c) a exogeneidade só é relevante para identificar as relações contemporâneas. Por outro lado, as principais críticas em relação ao VAR são: a) consomem muitos graus de liberdade; e b) podem 
ter desempenho ruim diante de quebras estruturais e outras fontes de correlação serial nos resíduos. Contudo, acredita-se que a bateria de testes de diagnóstico reportada deve informar o leitor sobre a adequação do método empírico escolhido.

No tocante aos dados, deve-se ressaltar que o estudo adota séries "novas" da taxa de desemprego e das expectativas de inflação disponíveis para o Brasil. Como o IBGE descontinuou a série de desemprego em 2002, vários trabalhos prévios recorriam à taxa do estado de São Paulo (Fundação Sistema Estadual de Análise de Dados - Seade e Departamento Intersindical de Estatística e Estudos Socioeconômicos - Dieese) como proxy. Isso constitui uma simplificação grande, pois supõe que a dinâmica do emprego no Brasil como um todo é similar ao que ocorre em São Paulo. Além de usar a nova série de desemprego do IBGE, outro detalhe importante é o uso das expectativas de inflação disponibilizadas pelo Banco Central do Brasil (BCB) no boletim Focus. Como essa série começa em 2001, poucos foram os trabalhos que puderam usar esses dados em estimativas de séries temporais.

Este artigo conta com cinco seções, além desta introdução. A seção 2 traça um panorama da literatura empírica para o Brasil; as seções 3 e 4 apresentam os dados e o método empírico; a seção 5 reporta os resultados encontrados; e, por fim, a seção 6 traz as considerações finais.

\section{Literatura}

A importância tanto teórica quanto empírica tem despertado a atenção dos pesquisadores brasileiros em relação à curva de Phillips. Vários estudos tentam estimar não somente a curva de Phillips para o Brasil, mas também, a partir desta, fazer inferências sobre a adequação da política monetária, o sucesso do regime de metas de inflação, o grau de rigidez salarial da economia brasileira e a taxa de desemprego que não acelera a inflação.

De maneira geral, os trabalhos que estimam a curva de Phillips para o Brasil se diferenciam tanto pelo período amostral utilizado, quanto pelas variáveis adotadas nas regressões e pelos métodos estatísticos empregados. O objetivo desta seção é revisar uma ampla gama de estudos que analisam a curva de Phillips para a realidade brasileira.

Fazendo uso de dados trimestrais para o período de 1982 a 1998, Portugal, Madalozzo e Hilllbrecht (1999) encontram uma estimativa linear do trade-off entre inflação e desemprego que tem significância estatística e aparentemente é adequada aos dados da economia brasileira. Como proxy para a inflação, adotam o Índice Nacional de Preços ao Consumidor (INPC) elaborado pelo IBGE. Para representar a taxa de desemprego, utilizam tanto a Pesquisa Mensal de Emprego (PME) do IBGE, quanto a Pesquisa de Emprego e Desemprego (PED) do Dieese e da Fundação Seade. Na PED, utilizam apenas os dados referentes ao estado de São 
Paulo. Para obter a inflação esperada, estimam vários modelos autorregressivos integrados de média móvel (Arima) e escolhem aquele que gera a melhor predição para a taxa de inflação. Como o objetivo principal dos autores é estimar a taxa de desemprego que não acelera a inflação (Nairu), a variável dependente em suas estimativas é a inflação atual menos a inflação esperada para o próximo período. Com os dados do IBGE, encontram um coeficiente de 0,185 para a primeira defasagem dessa variável e um de 0,123 para a segunda, sendo ambas estatisticamente insignificantes. Já para o desemprego, encontram um coeficiente estatisticamente significante da ordem de -1,745.

Em outro artigo, Portugal e Madalozzo (2000) confirmam que a estimação de um formato linear para a curva de Phillips apresentou significância estatística e adaptou-se de maneira bastante adequada ao caso brasileiro. Eles estimam a Nairu usando dados tanto do IBGE quanto do Dieese, e os resultados mostram uma curva de Phillips linear para o Brasil. Esse artigo utiliza dados trimestrais para o período de 1982 a 1997. As proxies adotadas são: a) inflação: INPC do IBGE; b) desemprego: desemprego aberto, 30 dias (tanto da PME do IBGE quanto da PED do Dieese); e c) inflação esperada: estima-se um AR(1). Novamente, a variável dependente em suas estimativas é a inflação atual menos a inflação esperada para o próximo período. Com os dados do IBGE, os autores encontram um coeficiente de 0,29 para a primeira defasagem e um de 0,21 para segunda, sendo ambas insignificantes. Já para o desemprego, encontram um coeficiente estatisticamente significante de $-3,37$.

Lima (2003) estima a Nairu para o Brasil e verifica a estabilidade dos coeficientes da curva de Phillips brasileira. São estimados dois modelos diferentes em espaço de estados: um com uma Nairu que muda ao longo do tempo e outro no qual a Nairu muda de acordo com a especificação de uma cadeia de Markov oculta. Os resultados econométricos sugerem que a inclinação da curva de Phillips do Brasil é estável, porém a Nairu brasileira vem se alterando ao longo do tempo. Os modelos foram estimados com dados trimestrais para o período de 1982 a 2001 . A proxy adotada para a inflação foi o INPC e para o desemprego utilizou-se a taxa de desemprego aberto da PME do IBGE. Para lidar com as possíveis quebras estruturais inerentes a esse período da economia brasileira, o autor estima modelos com mudança nos parâmetros e resíduos ARCH e outro com mudança nos parâmetros ao longo do tempo e regimes Markov-switching. Os resultados econométricos não possibilitam a rejeição da hipótese de estabilidade da curva de Phillips. Existe uma relação estatisticamente significante entre o desemprego cíclico e a mudança na taxa de inflação. De acordo com o primeiro (segundo) modelo, um aumento permanente de $0,5 \%$ do desemprego cíclico, depois de três (um) trimestres, reduz em $7,5 \%(5 \%)$ a taxa mensal anualizada de inflação. Considerando-se a incerteza sobre 
qual modelo é o mais adequado, adicionada do intervalo de confiança, tem-se que qualquer resposta da inflação entre $-11 \%$ e $-4 \%$ não pode ser rejeitada.

Numa análise para o período de 1995 a 2002 com dados mensais, Minella et al. (2003) constatam que a inflação esperada reage significativamente à meta de inflação. Eles concluem que essa correlação é um indício de que as metas de inflação são importantes determinantes das expectativas inflacionárias. Como proxy para a inflação, adotam o Índice de Preços ao Consumidor Amplo (IPCA) e para o desemprego utilizam a taxa de desemprego sazonalmente ajustada de sete dias do IBGE (também reportam que os resultados são similares para o caso de dados brutos ou de 30 dias). Encontram os seguintes parâmetros para a curva de Phillips: a inflação passada varia entre 0,56 e 0,62 (para o caso em que uma segunda defasagem de inflação é incluída, seu coeficiente é de -0,09, mas é estatisticamente igual a zero); o desemprego passado varia entre -0,08 (não significativo) e - 0,09 (significativo, ocorre quando se inclui a segunda defasagem da inflação).

Fasolo e Portugal (2004) testam a relação entre inflação e emprego no Brasil com o uso de quatro hipóteses novo keynesianas: a) agentes não possuem racionalidade perfeita; b) imperfeição na formação de expectativas pode ser determinante no componente inercial da inflação brasileira; c) inflação possui componente inercial autônomo; e d) relações não lineares entre inflação e desemprego fornecem melhores resultados para a economia nos últimos 12 anos. A curva de Phillips é estimada com o auxilio do filtro de Kalman e a relação entre inflação e expectativas é verificada por um modelo de mudança de regime. Os dados são mensais e se referem ao período de 1990 a 2002. Em relação às variáveis inflação e desemprego, as proxies consideradas foram o IPCA e o desemprego aberto, 30 dias, sazonalmente ajustado do IBGE. Os testes econométricos confirmam todas as hipóteses mencionadas anteriormente. Além disso, mostram que a curva de Phillips para o Brasil deve ser estimada levando em consideração algum tipo de não linearidade. Os coeficientes encontrados foram 0,13 para a inflação passada, 0,82 para a inflação futura e 74,23 para o hiato do desemprego. Na subamostra que vai de 1990 a junho de 1994, o coeficiente da inflação passada foi de 0,30 e o da inflação futura de 0,44. Já no período de 1995 a agosto de 2002, o parâmetro referente à inflação passada foi estimado em 0,10 e o da inflação futura em -0,04 (não significante).

Muinhos (2004) adota dados trimestrais cobrindo o período que vai do final de 1994 a meados de 2002. O hiato do produto, mensurado como desvio do PIB em relação a uma tendência linear, é usado para representar os custos marginais, enquanto a proxy usada para a inflação é o IPCA, e a expectativa de inflação é obtida através de um modelo Autorregressivo de Médias Móveis (Arma). É interessante notar que o artigo não inclui a inflação passada e a expectativa de inflação juntas nas mesmas regressões. Dessa forma, uma estimativa linear da curva de Phillips obteve coeficientes de 0,51 para a inflação passada e 0,28 para o hiato do 
produto, enquanto, em outra, as estimativas foram de 1,18 para a expectativa de inflação e 0,35 para o hiato do produto. Por outro lado, uma estimativa não linear gerou coeficientes de 0,45 para a inflação passada e 0,41 para o hiato do produto, e, na outra, as estimativas foram de 1,29 para a expectativa de inflação e 0,31 para o hiato do produto.

Alves e Areosa (2005) fazem uma contribuição teórica ao incluir a meta de inflação na curva de Phillips. Eles derivam a curva de Phillips novo keynesiana incorporando a indexação não apenas por meio da inflação passada, mas também pela meta de inflação. Como proxies adotam o IPCA para a inflação e constroem uma variável que representa o custo marginal agregado das firmas (índice de salário real vezes a força de trabalho ocupada, tudo dividido pela parcela da renda do trabalho vezes o PIB), mas essa variável se refere apenas à região metropolitana de São Paulo (dados da Fundação Seade). Os dados são trimestrais do período de 1995 a 2004 e os coeficientes encontrados foram de -0,11 para o custo marginal (não significativo) e de 0,68 para a meta de inflação.

Schwartzman (2006) realiza estimativas da curva de Phillips para o Brasil a partir de dados de preços desagregados fazendo uso do método de mínimos quadrados em três estágios. Foram usados dados trimestrais para diferentes amostras, começando em 1997, 1998 e 1999 e terminando todas no terceiro trimestre de 2003. Como proxy para o custo marginal das empresas, o autor adota a utilização da capacidade da indústria calculada pela Fundação Getúlio Vargas (FGV) e para a inflação futura e passada utiliza o IPCA cheio. Já as expectativas de inflação foram modeladas a partir de um VAR. A grande novidade desse estudo reside no fato de regredir conjuntamente três grupos de preços (comercializáveis, não comercializáveis e monitorados) na estimação da curva de Phillips. Foram estimadas variações do modelo básico para testar o efeito de algumas das diferentes opções de modelagem realizadas pela literatura. De forma geral, não foi possível rejeitar a hipótese de verticalidade de longo prazo da curva de Phillips, de forma que esta parece ser uma boa hipótese de trabalho ao se analisar a economia brasileira. Os coeficientes encontrados para a equação de não comercializáveis ficaram entre 0,71 e 1,27 para a capacidade instalada e entre 0,39 e 0,50 para a inflação passada. Já na equação de comercializáveis, a estimativa para a inflação passada ficou entre 0,97 e 0,56 .

Tombini e Alves (2006) desagregam o IPCA em dois componentes: mercado livre e preços monitorados. O hiato do produto é a proxy usada para representar o custo marginal das firmas, como em boa parte dos estudos. O período analisado vai de 1996 até janeiro de 2006. Os coeficientes para a inflação passada e futura (variáveis em logaritmo) ficaram entre 0,3 e 0,1 . Aqui cabe observar que os autores estimam uma curva de Phillips híbrida com parâmetros variáveis com o auxílio do filtro de Kalman e concluem que vários parâmetros se movem para patamares 
distintos em ao menos duas ocasiões: na mudança para câmbio flexível em 1999 e no meio de 2002.

O artigo de Mendonça e Santos (2006) avalia se a incorporação de uma medida de credibilidade da política monetária melhora o poder de previsão da curva de Phillips brasileira no período posterior à introdução do regime de metas para inflação. Os resultados encontrados indicam que a utilização de uma medida de credibilidade pode prover um modelo com qualidade de previsão superior àquelas obtidas por modelos que impõem uma relação estável entre a inflação e as expectativas de inflação. Como proxy para o desemprego adotam a taxa de desemprego aberto da PED do Dieese da região metropolitana de São Paulo. A expectativa de inflação é estimada utilizando a série de expectativas de inflação (medidas pelo IPCA) disponibilizadas pelo BCB. Os parâmetros encontrados são: entre 0,43 e 0,96 para a inflação esperada; entre -0,09 e -0,16 para o hiato do desemprego (taxa natural menos taxa de desemprego); e entre -0,01 e -0,08 para a primeira diferença do hiato do desemprego.

Areosa e Medeiros (2007) derivam e estimam um modelo estrutural para inflação numa economia aberta. O modelo representa a curva de Phillips novo keynesiana padrão e uma curva híbrida. Na parte econométrica usam dados mensais para o período de 1995 a 2003. A inflação é mensurada pelo IPCA e duas proxies para o custo marginal das empresas são consideradas: a renda do trabalho na produção e o hiato do produto (produção industrial do IBGE regredida contra 11 dummies sazonais e uma tendência linear). Os resultados econométricos para a economia fechada (estimativa por Método Generalizado dos Momentos - GMM) foram: a) a inflação passada é um componente não negligível, com estimativas ao redor de 0,45; b) a inflação futura é dominante, com valores ao redor de 0,53; e c) o impacto dos custos marginais não é estatisticamente significante e tem um efeito negligível. Já para a economia aberta, os resultados indicam que: a) a inflação passada tem coeficiente menor do que no caso da economia fechada, variando entre 0,10 e 0,37 ; b) a inflação futura mostra valores maiores que no caso da economia fechada, variando entre 0,63 e 0,81; e c) o impacto dos custos marginais, apesar de ser irrelevante em magnitude, é positivo e estatisticamente significante.

Arruda, Ferreira e Castelar (2011) adotam modelos não lineares da curva de Phillips para fins de previsão. Eles argumentam que a curva de Phillips ampliada com efeito limiar é a que apresenta o melhor desempenho em termos preditivos. Segundo os autores, num regime com taxa de inflação de quatro meses abaixo de $0,17 \%$, os efeitos da inércia inflacionária e do repasse cambial são estatisticamente insignificantes. Contudo, no regime em que a inflação dos quatro meses passados supera a marca de $0,17 \%$, os efeitos do repasse cambial e da inércia inflacionária aumentam e se tornam estatisticamente significantes. Porém, em ambos os casos, o hiato do produto não se mostrou estatisticamente significante. 
Sachsida, Ribeiro e Santos (2009) estimam a curva de Phillips por meio de modelos não lineares. Eles mostram que os resultados são extremamente sensíveis tanto às proxies adotadas para representar o custo marginal das empresas quanto também às especificações de linearidade adotadas. Corroborando esse resultado, Sachsida e Mendonça (2009), num estudo de dados de painel para seis regiões metropolitanas brasileiras, apontam a inadequação da curva de Phillips em representar a dinâmica inflacionária brasileira.

Mazali e Divino (2010) estimam a curva de Phillips para a economia brasileira com dados trimestrais para o período de 1995 a 2008. Todas as variáveis são logaritmizadas e eles adotam as seguintes proxies: IPCA para mensurar a inflação e, no caso do custo marginal, usam taxa de desemprego aberto sazonalmente ajustada da região metropolitana de São Paulo, calculada pelo Dieese. Por sua vez, a inflação esperada é estimada por variáveis instrumentais. O método GMM é empregado para estimar os parâmetros da curva de Phillips. Vale ressaltar que esse artigo é um dos poucos a se preocupar seriamente com a ordem de integração das séries, concluindo, após uma bateria de testes, que todas as variáveis são estacionárias. Os resultados econométricos são consistentes com a teoria, mostrando um bom grau de ajustamento da curva de Phillips aos dados brasileiros. Os parâmetros encontrados foram de 0,59, para a inflação passada, de 0,44, para a inflação futura, e de $-0,13$ para o desemprego.

Entre os estudos recentes sobre a curva de Phillips para a economia brasileira, é importante destacar também o trabalho de Areosa, McAleer e Medeiros (2011). Eles salientam a importância de modelos não lineares para explicar a evolução da dinâmica inflacionária brasileira e defendem a existência de dois regimes: o primeiro de baixa incerteza e o segundo de alta incerteza. Segundo o estudo, a inércia inflacionária só seria relevante no regime de baixa incerteza, ao passo que o hiato do produto só seria significante quando a incerteza inflacionária fosse alta. Isto é, a variável de custo marginal (hiato do produto nesse caso) teria habilidade para explicar a dinâmica inflacionária apenas em situações de alta incerteza.

Sachsida, Mendonça e Medrano (2011) estimam uma curva de Phillips com choques cambiais para a economia brasileira com várias especificações, diferentes conjuntos de dados, distintos períodos de tempo e diferentes frequências. Além disso, adotaram quatro metodologias econométricas distintas (metodologia frequentista e bayesiana nas análises de séries temporais, modelo de transição suave com regressores endógenos e modelos de dados em painel) para verificar o efeito da taxa de desemprego e da taxa de câmbio sobre a inflação. Os resultados econométricos se mostraram robustos para no curto prazo: a) negar a importância do desemprego e do choque cambial sobre a inflação; b) destacar a importância das expectativas de inflação; e c) confirmar, na grande maioria dos casos, a restrição 
proposta por Blanchard e Galí (2007) de que a soma dos coeficientes da inflação passada e da expectativa de inflação deve ser igual à unidade.

\section{Dados}

As variáveis escolhidas para o presente estudo estão em conformidade com a dinâmica da inflação na perspectiva novo keynesiana. A inflação hoje é uma função da expectativa de inflação para o período seguinte e do custo marginal das empresas. Em uma economia aberta, os choques na taxa de câmbio se tornam relevantes.

Especificamente, são consideradas quatro variáveis na estimação VAR da curva de Phillips:

a) choques cambiais $(\Delta \theta)$ : mensurados como a primeira diferença no logaritmo da taxa de câmbio nominal média no mês (média entre as taxas de compra e venda); as cotações da taxa de câmbio foram obtidas no site do BCB (séries 3697 e 3698 do sistema gerenciador de séries temporais);

b) taxa de desemprego aberto (U): é a proxy para o custo marginal das firmas; a fonte dos dados é a PME do IBGE (a série específica trabalhada encontra-se na tabela 177, intitulada "Taxa de desocupação na semana de referência, das pessoas de 10 anos ou mais de idade, por regiões metropolitanas, segundo os meses da pesquisa"); os dados abrangem as regiões metropolitanas de todo o Brasil - essa é uma distinção importante em relação aos trabalhos prévios que usaram a taxa de desemprego do estado de São Paulo;

c) inflação $(\pi)$ : utiliza-se o IPCA, que também é calculado pelo IBGE e mede o custo de vida para famílias com rendimentos mensais de 1 a 40 salários mínimos;

d) a expectativa de inflação $(\mathrm{E}(\pi))$ é a média mensal das previsões de mercado para o IPCA do mês seguinte. Essas previsões são divulgadas pelo BCB através de seu boletim Focus.

As séries de tempo são mostradas na Figura 1. Os dados cobrem os meses de março de 2002 a março de 2011 (totalizando 109 observações). Deve-se notar que o IBGE alterou a metodologia de cálculo da taxa de desemprego em 2002 e que a série do BCB de expectativas para a inflação do IPCA só começa em $2001{ }^{1}$

$1 \quad$ Este estudo não examina a existência ou não de raízes unitárias nas séries temporais. Quanto a isso, o leitor pode consultar o trabalho de Mazali e Divino (2010), que fazem uma bateria de testes e concluem que as séries brasileiras de inflação e desemprego são estacionárias. Vale notar, ademais, que Sims, Stock e Watson (1990) mostram que as funções de impulso resposta do VAR continuam válidas mesmo que algumas séries não sejam estacionárias. 
Figura 1 - Séries temporais (2002 a 2011)


Fonte: Elaboração própria a partir de dados do Banco Central e do IBGE.

\section{Método}

As análises acerca das propriedades da curva de Phillips brasileira foram feitas com base no método VAR que inclui choques cambiais, além da taxa de desemprego, expectativas de inflação e a inflação efetiva. O modelo empírico pode ser escrito como segue:

$$
Y_{t}=\sum_{i=1}^{p} \Phi_{i} Y_{t-i}+\Gamma_{t}+v_{t} \quad(t=1, \ldots, T+p),
$$

no qual $Y_{t}$ e $v_{t}$ são vetores $4 \times 1$ de dados e erros de previsão (ruído branco), ao passo que $\Phi_{i}$ é uma matriz 4 x 4 de coeficientes e $\Gamma_{t}$ contém os termos deterministas (constante, tendência e dummies diversas).

A representação na forma de um vetor de médias móveis (VMA) é bastante útil para compreender as análises empreendidas:

$$
Y_{t}=\Pi_{t}+\sum_{i=0}^{\infty} \Lambda^{i} v_{t-i}
$$


em que $\prod_{t}=\left(\mathrm{I}_{\mathrm{N}}-\sum_{\mathrm{i}=0}^{\mathrm{p}} \Phi_{\mathrm{i}} \mathrm{L}^{\mathrm{i}}\right)^{-1} \Gamma_{\mathrm{t}}$ e $\sum_{\mathrm{i}=0}^{\infty} \Lambda^{\mathrm{i}}=\left(\mathrm{I}_{\mathrm{N}}-\sum_{\mathrm{i}=0}^{\mathrm{p}} \Phi_{\mathrm{i}} \mathrm{L}^{\mathrm{i}}\right)^{-1}$ seguem da condição de estabilidade ( $L$ é o operador de defasagens). ${ }^{2}$

A dinâmica das variáveis endógenas é examinada principalmente com base nas funções de resposta a impulso (FRIs). Porém, as simulações consideram inovações ortogonais $\left(\epsilon_{t}\right)$ e não os erros de previsão $\left(v_{t}\right)$. Para identificar esses choques, deve-se expressar os erros de previsão como sendo combinações lineares das inovações ortogonais. Para tal, considera-se a matriz $B$, que é 4 x 4 e mostra as relações contemporâneas: ${ }^{3}$

$$
v_{t}=B \epsilon_{t}
$$

em que $v_{t} \sim\left(0, \Sigma_{v}\right)$ e $\epsilon_{t} \sim\left(0, \Sigma_{\epsilon}\right)$, e, sendo $\Sigma_{\epsilon}$ diagonal (pois as inovações são ortogonais) e $\Sigma_{v}$ não (pois em v, há correlação cruzada).

No tocante às matrizes de covariância, a equação 3 acarreta:

$$
\Sigma_{v}=\mathrm{B}_{\epsilon} \mathrm{B}^{\prime}
$$

Aqui deve-se observar que o VAR é subdeterminado: se $n$ é o número de variáveis, então há $n(n+1) / 2$ elementos na matriz $\Sigma_{v}$, através dos quais é preciso identificar $n^{2}$ parâmetros ( $n(n-1)$ em $B$ e outros $n$ em $\Sigma_{\epsilon}$ ). Portanto, a fim de tornar o modelo exatamente identificado, faz-se necessário impor $n(n-1) / 2$ restrições em $B$.

Como o modelo da curva de Phillips conta com quatro variáveis, deve-se impor um total de seis restrições. Com esse intuito, supõe-se que $B$ é triangular inferior:

$$
\mathrm{B}=\left(\begin{array}{cccc}
1 & 0 & 0 & 0 \\
b_{2,1} & 1 & 0 & 0 \\
b_{3,1} & b_{3,2} & 1 & 0 \\
b_{4,1} & b_{4,2} & b_{4,3} & 1
\end{array}\right)
$$

Isso nada mais é do que a fatoração de Cholesky aplicada na matriz de covariância dos erros. Essa estrutura é conhecida como wold causal chain.

Por fim, cumpre observar que essa decomposição de $\Sigma_{v}$ é única apenas para determinada ordenação das variáveis no vetor $Y_{t}$. Com efeito, se a ordem das variáveis no VAR for alterada, então o fator de Cholesky não será mais B.

O ordenamento é feito da variável mais exógena para a mais endógena, segundo a teoria. Portanto, a primeira variável é o choque cambial, a segunda é a taxa de desemprego, a terceira é a expectativa de inflação e, por último, a inflação.

$2 \quad$ A condição de estabilidade diz que as raízes da equação $\operatorname{det}\left(\mathrm{I}_{\mathrm{N}}-\Phi_{1} \mathrm{~L}^{1}+\cdots+\Phi_{\mathrm{p}} \mathrm{L}^{\mathrm{p}}\right)$ devem se situar fora do círculo unitário no domínio complexo.

3 Há vasta literatura sobre identificação de choques no VAR. Amisano e Giannini (1997) e Lütkepohl (2007) são boas referências. 
Deve estar claro que se supõe que: a) o choque na taxa de câmbio não é afetado contemporaneamente pelas demais variáveis endógenas; b) a taxa de desemprego é afetada pelas expectativas de inflação e pela inflação efetiva com defasagem de um período; c) as expectativas são afetadas pela inflação também com defasagem de um período; e d) choques em todas as outras variáveis podem afetar a inflação no mesmo período.

\section{Resultados}

Esta seção apresenta os principais resultados das análises empreendidas. Ela está dividida em duas partes: diagnóstico do modelo e dinâmica das variáveis endógenas diante de choques.

\subsection{Diagnóstico}

A especificação do VAR inclui somente uma defasagem (indicado pelo critério de Schwarz). De fato, mais lags sobreparametrizam o modelo sem melhorar de forma significante as propriedades dos resíduos. A Tabela 1 mostra uma síntese dos resultados.

Tabela 1 - Regressões***

\begin{tabular}{|c|c|c|c|c|}
\hline \multicolumn{5}{|c|}{$\begin{array}{c}\text { Periodo amostral: mar. } 2002 \text { a mar.201 } 1 \\
\text { Método: MQO }\end{array}$} \\
\hline & $\Delta \theta_{\mathrm{t}}$ & $U_{t}$ & $\mathrm{E}_{\mathrm{t}}\left(\pi_{\mathrm{t}+1}\right)$ & $\pi_{\mathrm{t}}$ \\
\hline \multirow[t]{2}{*}{$\Delta \theta_{t-1}$} & 0,35 & 1,94 & 0,09 & 1,49 \\
\hline & $(0,00)$ & $(0,33)$ & $(0,81)$ & $(0,28)$ \\
\hline \multirow{2}{*}{$\mathrm{U}_{\mathrm{t}-1}$} & 0,00 & 0,89 & $-0,01$ & $-0,05$ \\
\hline & $(0,43)$ & $(0,00)$ & $(0,21)$ & $(0,18)$ \\
\hline \multirow[t]{2}{*}{$E_{t-1}\left(\pi_{t}\right)$} & $-0,01$ & 0,07 & 0,55 & 0,44 \\
\hline & $(0,42)$ & $(0,78)$ & $(0,00)$ & $(0,01)$ \\
\hline \multirow[t]{2}{*}{$\pi_{\mathrm{t}-1}$} & 0,00 & $-0,01$ & 0,09 & 0,53 \\
\hline & $(0,85)$ & $(0,90)$ & $(0,00)$ & $(0,00)$ \\
\hline \multirow[t]{2}{*}{ constante } & 0,04 & 1,35 & 0,32 & 0,72 \\
\hline & $(0,31)$ & $(0,08)$ & $(0,03)$ & $(0,18)$ \\
\hline \multirow[t]{2}{*}{ tendência } & 0,00 & $-0,01$ & 0,00 & 0,00 \\
\hline & $(0,16)$ & $(0,07)$ & $(0,21)$ & $(0,22)$ \\
\hline
\end{tabular}

Fonte: Elaboração própria.

Notas: "Entre parênteses estão os valores-p; " dummies de sazonalidade e intervenção foram omitidas. 
Quanto aos termos deterministas, o modelo conta com constante, tendência e dummies de sazonalidade. A presença da tendência determinista é justificada pela trajetória de queda da taxa de desemprego durante grande parte do período amostral. Esse fenômeno está ligado a transformações estruturais na economia brasileira, pois nenhuma outra variável endógena teve comportamento semelhante.

O tratamento da sazonalidade via dummies é uma escolha dos autores baseada na crença de que o tratamento prévio das séries poderia levar a distorções nos dados. Fora isso, cabe notar que dummies de intervenção se mostraram necessárias para melhorar as propriedades dos resíduos. As observações "apagadas" por esse expediente estão geralmente associadas a grandes instabilidades macroeconômicas. ${ }^{4}$ Na sequência são discutidas as principais propriedades dos resíduos. ${ }^{5}$

De acordo com a Tabela 2, não há sinais de problemas graves de autocorrelação nesse modelo. Isso porque o teste Breusch-Godfrey não rejeita a ausência de correlação a 5\% de significância nas 12 primeiras defasagens. Porém, rejeita-se a hipótese nula nas defasagens cinco e seis a 10\% (sendo mais rigoroso, portanto). O teste Portmanteau, por sua vez, indica a existência de problemas nas primeiras defasagens. Deve-se notar que a inclusão de novos lags não melhora esse cenário.

Tabela 2 - Correlação serial"

\begin{tabular}{cccccccccc}
\hline $\mathbf{h}$ & $\mathbf{1}$ & $\mathbf{2}$ & $\mathbf{3}$ & $\mathbf{4}$ & $\mathbf{5}$ & $\mathbf{6}$ & $\mathbf{7}$ & $\mathbf{8}$ & $\mathbf{9}$ \\
\hline $\begin{array}{c}\text { Breus- } \\
\text { ch-Go- } \\
\text { dfrey }^{* *}\end{array}$ & 1,04 & 1,29 & 1,11 & 1,24 & 1,28 & 1,30 & 1,23 & 1,21 & 1,18 \\
& $(0,42)$ & $(0,14)$ & $(0,30)$ & $(0,13)$ & $(0,08)$ & $(0,06)$ & $(0,10)$ & $(0,12)$ & $(0,14)$ \\
$\begin{array}{c}\text { Port- } \\
\text { mante- } \\
\text { au*** }\end{array}$ & - & 31,93 & 43,00 & 61,00 & 78,80 & 93,60 & 105,60 & 129,30 & 142,70 \\
& $(0,01)$ & $(0,09)$ & $(0,10)$ & $(0,10)$ & $(0,14)$ & $(0,24)$ & $(0,13)$ & $(0,18)$ & $(0,00)$ \\
\hline
\end{tabular}

Fonte: Elaboração própria.

Notas: "Entre parênteses estão os valores-p (inclui correção para amostras finitas); " "teste LM (com aproximação F): hipótese nula é ausência de correlação na defasagem h; "*** teste $\chi^{2}$ : hipótese nula é ausência de correlação até a defasagem $\mathrm{h}$.

Além da correlação serial, deve-se observar que a não normalidade dos erros poderia também configurar um empecilho para a estratégia empírica escolhida, pois a estimação das FRIs é feita via máxima verossimilhança. Como mostram os resultados na Tabela 3, os resíduos seguem uma distribuição normal.

\footnotetext{
4 Os meses são os seguintes: junho e novembro de 2002, junho de 2003, junho de 2004 e setembro e outubro de 2008.

5 Ver Figura 6 no Apêndice A.
} 
Tabela 3 - Não normalidade*

\begin{tabular}{lrrr}
\hline \multicolumn{1}{c}{ JB $^{* *}$} & \multicolumn{1}{c}{$\chi^{\mathbf{2}}$} & Skewness & Kurtosis \\
\hline Doornik-Hansen & 9,34 & 6,33 & 3,01 \\
& $(0,31)$ & $(0,18)$ & $(0,56)$ \\
Lütkepohl & 7,84 & 5,13 & 2,71 \\
& $(0,45)$ & $(0,27)$ & $(0,61)$ \\
\hline
\end{tabular}

Fonte: Elaboração própria.

Notas: " Entre parênteses estão os valores-p; " Esses testes nada mais são do que versões multivariadas do teste Jarque-Bera (JB); a hipótese nula é sempre de normalidade.

\subsection{Simulações}

Nesta seção são mostradas as FRIs de todas as variáveis endógenas. Os choques são sempre iguais a um desvio padrão e o horizonte temporal considerado é de 24 meses. No caso da inflação, reporta-se também a decomposição da variância do erro de previsão.

O choque cambial é a única variável que afeta todas as demais contemporaneamente. A Figura 2 mostra a dinâmica ocorrida devido a uma inovação nessa variável. O choque é um pouco maior que $\mathrm{R} \$ 0,01$ no preço do dólar.

Figura 2 - FRIs: choque em $\Delta \theta^{*}$
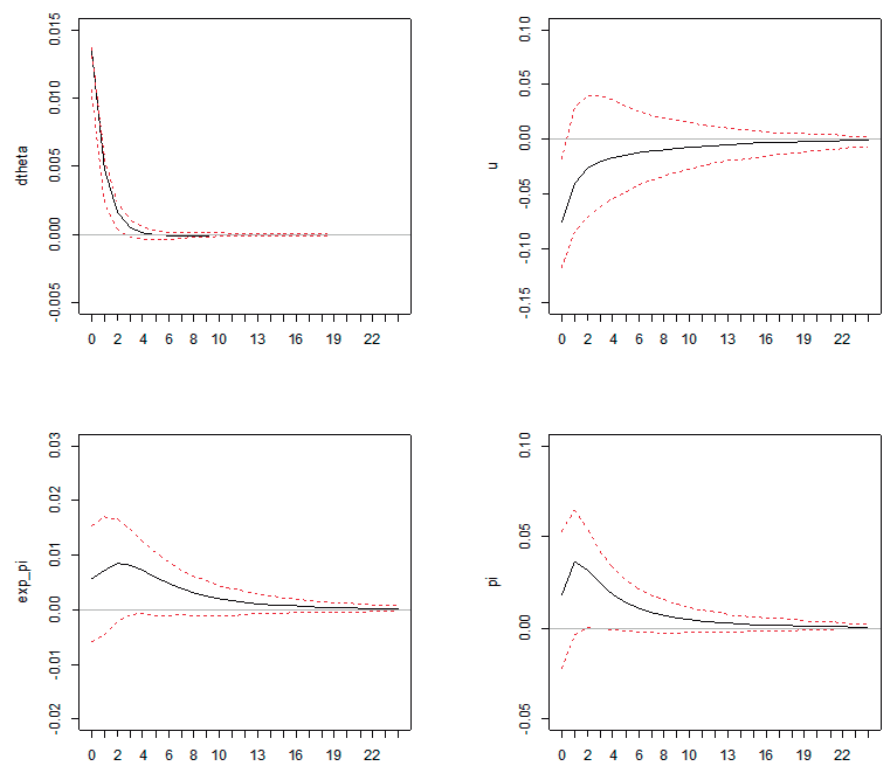

Fonte: Elaboração própria.

Notas: "Intervalos de confiança de $90 \%$ calculados via bootstrap. 
A série de choques cambiais apresenta persistência muito baixa e quase não responde a inovações em si mesmas (o efeito converge muito rápido para zero). No tocante às demais variáveis, deve-se observar que a magnitude do impacto é sempre relevante em termos econômicos (estimativa pontual), mas o efeito é estatisticamente diferente de zero só em alguns momentos.

No caso do desemprego, só o impacto contemporâneo é estatisticamente diferente de zero. A estimativa pontual é de -0.08 p.p. e a resposta decai rapidamente. No caso das expectativas de inflação, o efeito é sempre não significante. Em termos de estimativa pontual, a resposta máxima é de 0,008 p.p. no segundo mês após a inovação (0,10 p.p. na taxa anualizada). O efeito sobre a inflação é positivo e bem mais expressivo, mas também não é significante. A resposta máxima é de 0,036 p.p. (0,44 p.p. na inflação anualizada) no mês seguinte ao choque. ${ }^{6}$

A Figura 3 retrata o efeito de uma inovação na taxa de desemprego. De acordo com o ordenamento desta pesquisa, essa variável afeta tanto as expectativas, quanto a inflação propriamente dita de forma instantânea. A magnitude do choque é de 0,3 p.p.

Figura 3 - FRIs: choque em $U^{*}$
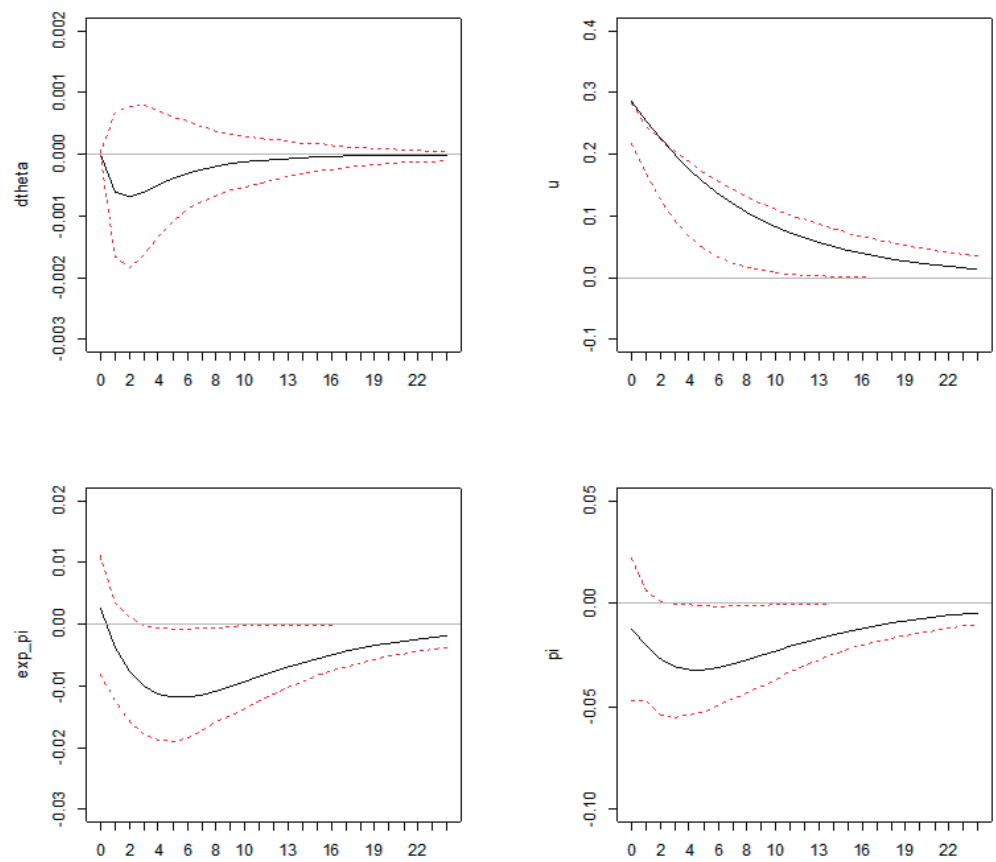

Fonte: Elaboração própria.

Nota: "Intervalos de confiança de $90 \%$ calculados via bootstrap.

6 O choque cambial apresentou impacto contemporâneo e efeitos defasados positivos tanto na inflação, quanto nas expectativas (estimativa pontual). Dessa forma, além da pressão direta nos preços via pass-through, há também o efeito indireto através das expectativas (ver Figura 4). 
A taxa de desemprego é a mais persistente de todas as séries (mesmo nesse modelo com tendência determinista), uma vez que a inovação só se dissipa após um ano. No que diz respeito ao choque cambial, deve-se observar que essa variável não é afetada pela inovação na taxa de desemprego ao longo de todo o horizonte de simulação. Com efeito, nenhuma outra variável endógena afeta o choque cambial, o que não surpreende.

As respostas das expectativas e da inflação efetiva são negativas. No caso das expectativas, o impacto é significante e atinge -0,012 p.p. (-0,14 p.p. na taxa anualizada) entre o quinto e o sexto mês depois do choque. No que se refere à inflação, a estimativa pontual prevê um impacto máximo de -0,032 p.p. (-0,38 p.p. na inflação anualizada) em torno do quarto mês que segue a inovação.

A Figura 4 mostra as respostas a um choque na expectativa de inflação. $\mathrm{O}$ tamanho do choque é de 0,058 p.p. (equivalente a 0,7 p.p. na taxa anualizada). A taxa de desemprego, assim como os choques cambiais apresentaram respostas próximas de zero e não significantes, ao passo que o efeito sobre a inflação é significante e de magnitude considerável. Isto é, a inovação nas expectativas é carregada para a inflação. $\mathrm{O}$ impacto atinge um máximo de 0,049 p.p. no mês seguinte ao choque (acréscimo de 0,59 p.p. na inflação anualizada).

Figura 4 - FRIs: choque em $E(\pi)^{*}$
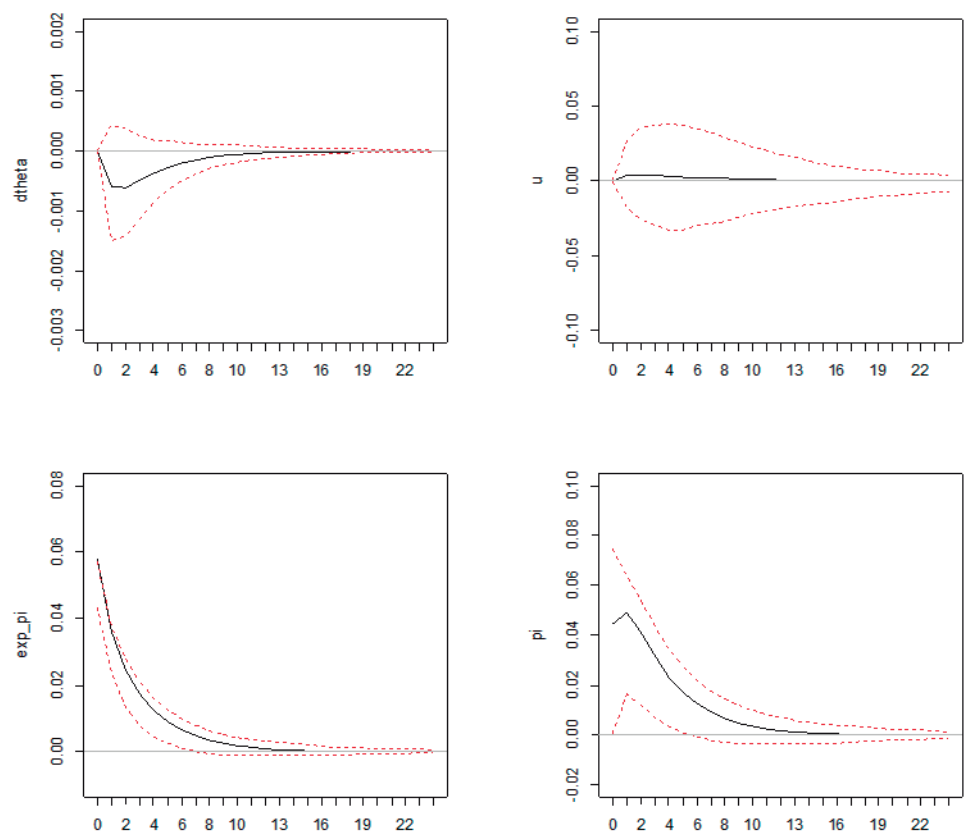

Fonte: Elaboração própria.

Nota: "Intervalos de confiança de $90 \%$ calculados via bootstrap. 
De fato, os choques nas expectativas são a principal fonte de variância nos erros de previsão da inflação dentro de um ano, desconsiderando inovações na própria variável. Já os choques na taxa de desemprego explicam parcela equivalente à das expectativas somente após cerca de dez meses. As estatísticas relevantes são apresentadas na Tabela 4.

Tabela 4 - Inflação $(\pi)$ : decomposição da variância dos erros de previsão"

\begin{tabular}{ccccc}
\hline Mês & $\boldsymbol{\Delta} \theta$ & $\mathbf{U}$ & $\mathbf{E}(\boldsymbol{\pi})$ & $\boldsymbol{\pi}$ \\
\hline 1 & 0,01 & 0,00 & 0,05 & 0,94 \\
2 & 0,03 & 0,01 & 0,08 & 0,88 \\
3 & 0,04 & 0,02 & 0,09 & 0,84 \\
4 & 0,05 & 0,03 & 0,10 & 0,82 \\
5 & 0,05 & 0,05 & 0,11 & 0,80 \\
6 & 0,05 & 0,06 & 0,11 & 0,78 \\
7 & 0,05 & 0,07 & 0,11 & 0,77 \\
8 & 0,05 & 0,08 & 0,11 & 0,76 \\
9 & 0,05 & 0,09 & 0,11 & 0,75 \\
10 & 0,05 & 0,10 & 0,11 & 0,75 \\
11 & 0,05 & 0,10 & 0,11 & 0,74 \\
12 & 0,05 & 0,11 & 0,10 & 0,74 \\
\hline
\end{tabular}

Fonte: Elaboração própria.

A Figura 5 mostra o impacto de um choque de 0,2 p.p. na taxa de inflação (aproximadamente 2,4 p.p. na taxa anualizada). De acordo com essas estimativas, mais inflação não reduz o desemprego. A única resposta significante, fora a da própria inflação, é das expectativas. No mês seguinte ao choque, o impacto é de 0,02 p.p. na expectativa para o próximo mês ( 0,24 p.p. em termos anualizados). 
Figura 5 - FRIs: choque em $\pi^{*}$
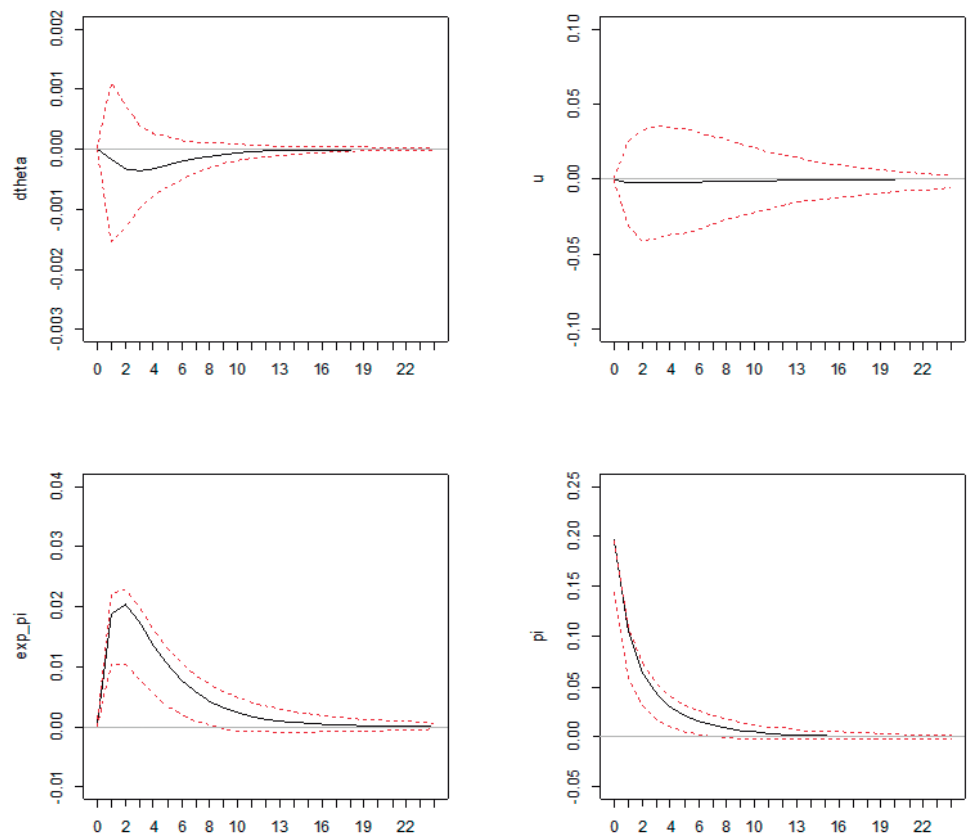

Fonte: Elaboração própria.

Nota: "Intervalos de confiança de $90 \%$ calculados via bootstrap.

Para encerrar, devem ser feitas duas ressalvas quantos aos resultados reportados neste trabalho. Primeiro, regressões com dados mensais são passíveis de críticas devido ao problema das defasagens. De fato, variáveis econômicas geralmente reagem com algum atraso a choques ou mudanças no ambiente de negócios. Quanto a isso, cumpre ressaltar que as principais indicações reportadas neste estudo se mantiveram em um exercício empírico similar realizado com dados trimestrais. Porém, as séries de tempos trimestrais são muito curtas e a incerteza é maior quanto a essas estimativas. ${ }^{7}$

Segundo, nosso modelo empírico considera as expectativas (que é uma variável endógena) como sendo independentes em termos de comportamento da inflação efetiva. Na prática, isso significa que o valor esperado das expectativas pode ser diferente da inflação no longo prazo. Isso, sem dúvida, é uma limitação. Devido a essa consideração, estimou-se um modelo em que as expectativas entram como variável exógena. Os resultados são apresentados no Apêndice B e evidenciam que a dinâmica das demais variáveis fica praticamente inalterada.

7 Esses resultados podem ser obtidos mediante contato direto com os autores. 
Não obstante esses fatos, os resultados principais encontrados estão de acordo com estimativas de trabalhos anteriores sobre a curva de Phillips brasileira, apesar das diferenças no método e no conjunto de dados. $O$ fato de que os choques cambiais explicam uma parte limitada da variância do erro de previsão da inflação está de acordo com Sachsida, Mendonça e Medrano (2011). Já a importância das expectativas está bem documentada na literatura. As pesquisas de Mazali e Divino (2010) e Areosa e Medeiros (2007) são exemplos de estudos que concluíram que essa variável é capaz de explicar uma parcela da dinâmica da inflação brasileira. Com relação ao custo marginal das empresas, os resultados existentes na literatura são diversos, pois as estimativas são muito sensíveis às proxies escolhidas. O efeito encontrado sobre a inflação foi negativo, conforme Minella et al. (2003), entre outros.

\section{Considerações Finais}

Este trabalho estimou um modelo VAR representando a curva de Phillips novo keynesiana com choques cambiais. O período analisado vai de março de 2002 a março de 2011. Quanto aos dados, cabe destacar que o estudo usou a taxa de desemprego da PME (que abrange as regiões metropolitanas, ao contrário da $\mathrm{PED}$, que é restrita a São Paulo), e as expectativas obtidas foram do boletim Focus do $\mathrm{BCB}$ (em vez de serem estimadas).

Os resultados podem ser sintetizados em quatro pontos principais: a) a série de desemprego é a mais persistente, e um choque leva mais de um ano para desaparecer, ao passo que os choques cambiais são pouco persistentes e não são afetados por nenhuma outra variável; b) os choques cambiais não afetam o desemprego, mas impactam a inflação (estimativa pontual positiva, mas insignificante); c) inovações na taxa de inflação contaminam as expectativas, e choques nas expectativas são carregados para a inflação; e d) choques positivos na taxa de desemprego podem reduzir tanto as expectativas, quanto a inflação em horizontes curtos de tempo (o efeito encontrado foi não significante sobre essa última variável), mas choques na inflação não impactam o desemprego, isto é, mais inflação não reduz o desemprego.

\section{Referências}

ALVES, S. A. L.; AREOSA, W. D. Targets and inflation dynamics. Brasília, DF: Central Bank of Brazil, 2005. (Working paper n. 100).

AMISANO, G.; GIANNINI, C. Topics in structural VAR econometrics. Springer-Verlag, 1997. 
ANNABLE, J. Adjusting wages for price inflation: the rational arrangements Phillips curve. Dec. 2007. (Working paper). Disponível em: <http://dx.doi.org/10.2139/ssrn.1045321>. Acesso em: 10 set. 2011.

ARAUJO, C. H. V.; AREOSA, M. B. M.; GUILLÉN, O. D. C. Estimating potential output and output gap for Brazil. In: ENCONTRO NACIONAL DE ECONOMIA DA ANPEC, 32., 2004, João Pessoa. Anais... João Pessoa: ANPEC, 2004.

AREOSA, W. D.; MCALEER, M.; MEDEIROS, M. C. Moment-based estimation of smooth transition regression models with endogenous variables. Journal of Econometrics, v. 165, n. 1, p. 100-111, 2011.

AREOSA, W. D.; MEDEIROS, M. Inflation dynamics in Brazil: the case of a small open economy. Brazilian Review of Econometrics, v. 27, n. 1, p. 131-166, 2007.

ARRUDA, E. F.; FERREIRA, R. T.; CASTELAR, I. Modelos lineares e não lineares da curva de Phillips para previsão da taxa de inflação no Brasil. Revista Brasileira de Economia, v. 65, n. 3, p. 237-252, 2011.

BANCO CENTRAL DO BRASIL. Focus: Relatório de Mercado. Disponível em: < http://www. bcb.gov.br/pec/GCI/PORT/readout/readout.asp > . Acesso em: 10 set. 2011.

BÅRDSEN, G.; JANSEN, E. S.; NYMOEN, R. Econometric evaluation of the new Keynesian Phillips curve. Oxford Bulletin of Economics and Statistics, v. 66, n. s1, p. 671-686, 2004.

BLANCHARD, O.; GALÍ, J. Real wage rigidities and the new Keynesian model. Journal of Money, Credit and Banking, v. 39, n. s1, p. 35-65, 2007.

CLARIDA, R.; GALÍ, J.; GERTLER, M. The science of monetary policy: a new Keynesian perspective. Cambridge, MA: NBER, 1999. (NBER Working Paper, n. 7147).

COGLEY, T.; SBORDONE, A. M. Trend inflation and inflation persistence in the new Keynesian Phillips curve. New York: Federal Reserve Bank of New York, 2006. (Staff Report n. 270).

CORREA, A. D. S.; MINELLA, A. Nonlinear mechanisms of the exchange rate pass-through: A Phillips curve model with threshold for Brazil. Revista Brasileira de Economia, v. 64, n. 3, 231-243, 2010.

FASOLO, A. M.; PORTUGAL, M. S. Imperfect rationality and inflationary inertia: a new estimation of the. Estudos Econômicos, v. 34, n. 4, p. 725-776, 2004.

GALÍ, J.; GERTLER, M.; LOPEZ SALIDO, J. D. European inflation dynamics. European Economic Review, v. 45, n. 7, p. 1237-1270, 2001.

. Robustness of the estimates of the hybrid new Keynesian Phillips curve. Journal of Monetary Economics, v. 52, n. 6, p. 1107-1118, 2005.

GALÍ, J.; GERTLER, V. Inflation dynamics: A structural econometric analysis. Journal of Monetary Economics, v. 44, n. 2, p. 195i222, 1999.

HARGREAVES, D.; KITE, H.; HODGETTS, B. Modelling new Zealand inflation in a Phillips curve. Reserve Bank of New Zealand Bulletin, v. 69, n. 3, p. 23-37, 2006. 
HENZEL, S.; WOLLMERSHÄUSER, T. The new Keynesian Phillips curve and the role of expectations: evidence from the CESifo world economic survey. Economic Modelling, v. 25, n. 5, 811-832, 2008.

KARANASSOU, M.; SNOWER, D. J. Inflation persistence and the Phillips curve revisited. Bonn: University of Bonn, 2006. (IZA Discussion paper n. 2600).

LIMA, E. C. R. The NAIRU, unemployment and the rate of inflation in Brazil. Revista Brasileira de Economia, v. 57, n. 4, p. 899-930, 2003.

LINDÉ, J. Estimating new-Keynesian Phillips curves: a full information maximum likelihood approach. Journal of Monetary Economics, v. 52, n. 6, p. 1135-1149, 2005.

LÜTKEPOHL, H. New introduction to multiple time series analysis. Springer, 2007.

MANKIW, N. G. The inexorable and mysterious tradeoff between inflation and unemployment. The Economic Journal, v. 111, n. 471, p. 45-61, 2001.

MANKIW, N. G.; REIS, R. Sticky information versus sticky prices: a proposal to replace the new Keynesian Phillips curve. Quarterly Journal of Economics, v. 117, n. 4, p. 1295-1328, 2002.

MAZALI, A. A.; DIVINO, J. A. Real wage rigidity and the new Phillips curve: the Brazilian case. Revista Brasileira de Economia, v. 64. n. 3, p. 291-306, 2010.

MENDONÇA, H. F.; SANTOS, M. A. L. Credibilidade da política monetária e a previsão do trade-off entre inflação e desemprego: uma aplicação para o Brasil. Revista Economia, v. 7, n. 2, p. 293-306, 2006.

MINELLA, A. et al. Inflation targeting in Brazil: constructing credibility under exchange rate volatility. Journal of International Money and Finance, v. 22, n. 7, p. 1015-1040, 2003.

MUINHOS, M. K. Inflation targeting in an open financially integrated emerging. Estudos Econômicos, v. 34, n. 2, p. 269-296, 2004.

PORTUGAL, M.; MADALOZZO, R. Um modelo de Nairu para o Brasil. Revista de Economia Política, v. 20, n. 4, p. 26-47, 2000.

PORTUGAL, M.; MADALOZZO, R.; HILLLBRECHT, R. Inflation, unemployment and monetary policy in Brazil. In: ENCONTRO NACIONAL DE ECONOMIA, 21., Belém, PA. Anais... Belém, PA: SBE, 1999.

RUDD, J.; WHELAN, K. New tests of the new Keynesian Phillips curve. Journal of Monetary Economics, v. 52, n. 6, p. 1167-1181, 2005.

SACHSIDA, A.; MENDONÇA, M. J. Reexaminando a curva de Phillips brasileira com dados de seis regiões metropolitanas. Rio de Janeiro: IPEA, 2009. (Texto de discussão n. 1430).

SACHSIDA, A.; MENDONÇA, M. J.; MEDRANO, L. A. Inflação, desemprego e choques cambiais: novas evidências para o Brasil. Rio de Janeiro: IPEA, 2011. (Texto de discussão n. 1661). 
SACHSIDA, A.; RIBEIRO, M.; SANTOS, C. H. A curva de Phillips e a experiência brasileira. Rio de Janeiro: IPEA, 2009. (Texto de discussão n. 1.429).

SBORDONE, A. M. Prices and unit labor costs: a new test of price stickiness. Journal of Monetary Economics, v. 49, n. 2, p. 265-292, 2002.

SCHWARTZMAN, F. F. Estimativa de curva de Phillips para o Brasil com preços desagregados. Economia Aplicada, v. 10, n. 1, p. 137-155. 2006.

SIMS, C. A.; STOCK, J. H.; WATSON, M. W. Inference in linear time series models with some unit roots. Econometrica: Journal of the Econometric Society, v. 58, n.1, p. 113-144, 1990.

SVENSSON, L. E. Open-economy inflation targeting. Journal of International Economics, v. 50, n. 1, p. 155-183, 2000.

TOMBINI, A. A.; ALVES, S. L. The recent Brazilian disinflation process and costs. Brasília, DF: Central Bank of Brazil, 2006. (Working paper n. 109).

\section{Apêndice A - Resíduos do VAR}

Figura 6 - Resíduos
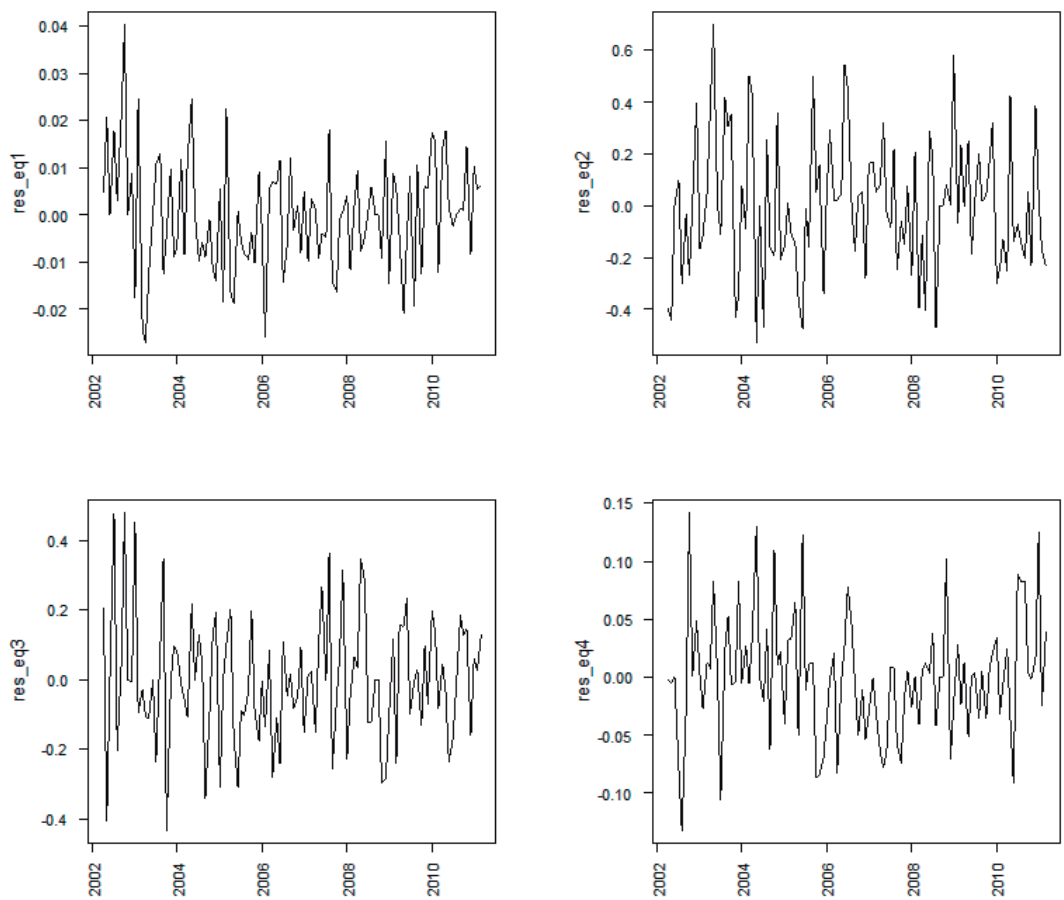

Fonte: Elaboração própria. 


\section{Apêndice B - Modelo VAR Alternativo com Expectativas Exógenas}

Tabela 5 - Regressões ${ }^{* * *}$

\begin{tabular}{|c|c|c|c|}
\hline \multicolumn{4}{|c|}{$\begin{array}{l}\text { Período amostral: mar-2002 a mar-201 } 1 \\
\text { Método: MQO }\end{array}$} \\
\hline & $\Delta \theta_{\mathrm{t}}$ & $U_{t}$ & $\pi_{\mathrm{t}}$ \\
\hline \multirow[t]{2}{*}{$\Delta \theta_{t-1}$} & 0,34 & 1,93 & 1,42 \\
\hline & $(0,00)$ & $(0,33)$ & $(0,29)$ \\
\hline \multirow[t]{2}{*}{$\mathrm{U}_{\mathrm{t}-1}$} & 0,00 & 0,89 & $-0,04$ \\
\hline & $(0,40)$ & $(0,00)$ & $(0,28)$ \\
\hline \multirow[t]{2}{*}{$\pi_{t-1}$} & 0,00 & $-0,02$ & 0,46 \\
\hline & $(0,61)$ & $(0,85)$ & $(0,00)$ \\
\hline \multirow[t]{2}{*}{ constante } & 0,03 & 1,32 & 0,47 \\
\hline & $(0,35)$ & $(0,10)$ & $(0,38)$ \\
\hline \multirow[t]{2}{*}{ tendência } & 0,00 & $-0,01$ & 0,00 \\
\hline & $(0,18)$ & $(0,08)$ & $(0,33)$ \\
\hline \multirow[t]{2}{*}{$E_{t-1}\left(\pi_{t}\right)$} & 0,00 & 0,11 & 0,79 \\
\hline & $(0,96)$ & $(0,75)$ & $(0,00)$ \\
\hline
\end{tabular}

Fonte: Elaboração própria.

Notas: "Entre parênteses estão os valores-p ; "*dummies de sazonalidade e intervenção foram omitidas. 
Figura 7 - FRIs: choque em $\Delta \theta^{*}$
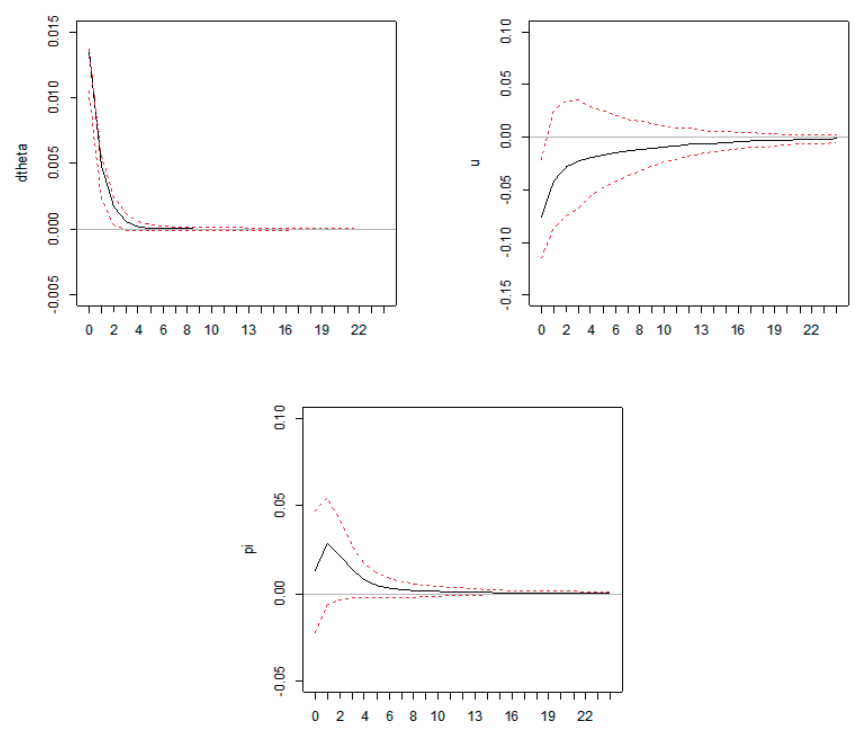

Fonte: Elaboração própria.

Nota: "Intervalos de confiança de 90\% calculados via bootstrap.

Figura 8 - FRIs: choque em $U^{*}$
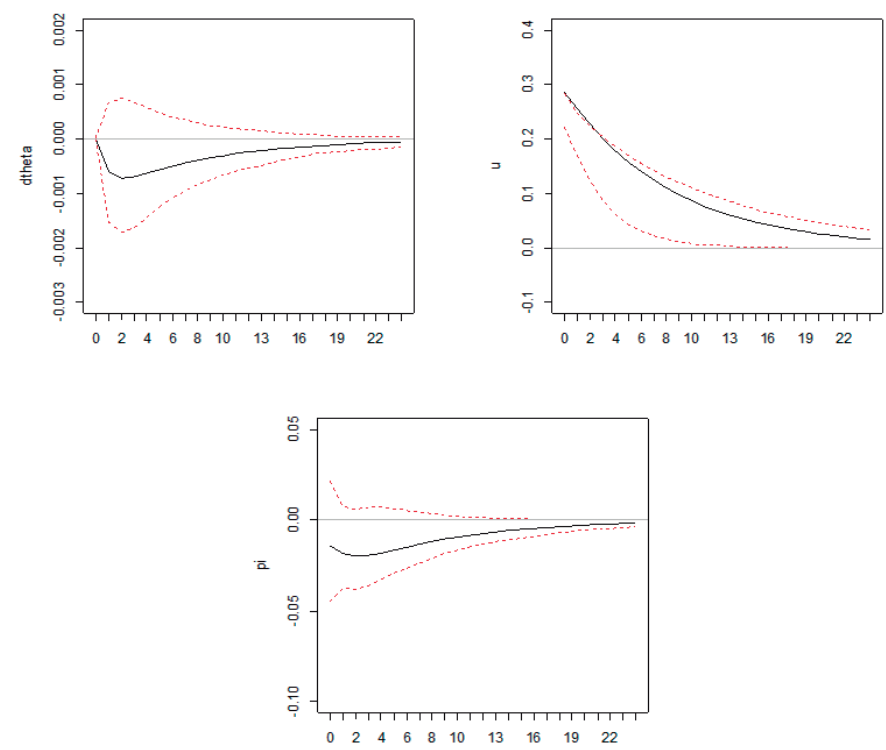

Fonte: Elaboração própria.

Nota: "Intervalos de confiança de $90 \%$ calculados via bootstrap. 
Figura 9 - FRIs: choque em $\pi^{*}$
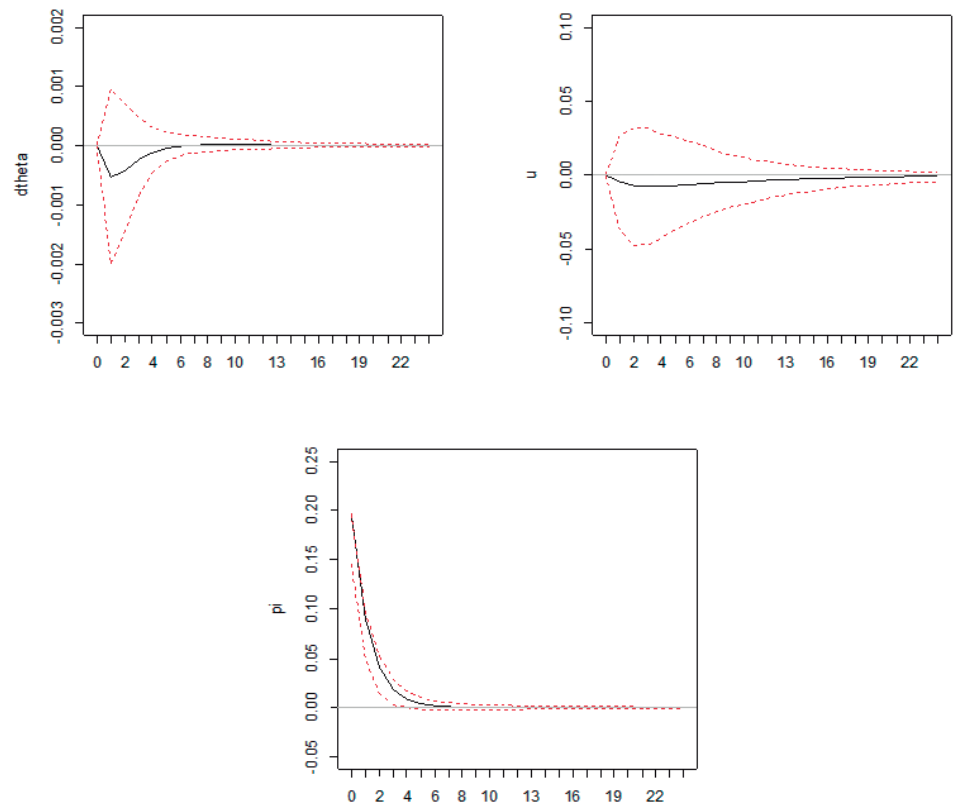

Fonte: Elaboração própria.

Nota: "Intervalos de confiança de $90 \%$ calculados via bootstrap.

Recebido em: 20/08/2015. Aceito em: 28/10/2015. 